\title{
Correlation between morphology and performance of low bandgap oligothiophene:C60 mixed heterojunctions in organic solar cells
}

\author{
D. Wynands, ${ }^{1, a)}$ M. Levichkova, ${ }^{1}$ M. Riede, ${ }^{1}$ M. Pfeiffer ${ }^{2}$ P. Baeuerle, ${ }^{3}$ R. Rentenberger ${ }^{4}$ \\ P. Denner, ${ }^{4}$ and K. Leo ${ }^{1}$ \\ ${ }_{1}^{1}$ Institut für Angewandte Photophysik, Technische Universität Dresden, 01062 Dresden, Germany \\ ${ }^{2}$ Heliatek GmbH, 01187 Dresden, Germany \\ ${ }^{3}$ Institut für Organische Chemie II und Neue Materialien, Universität Ulm, 89069 Ulm, Germany \\ ${ }^{4}$ Institut für Physik, Technische Universität Ilmenau, 98684 Ilmenau, Germany
}

(Received 16 October 2009; accepted 9 November 2009; published online 13 January 2010)

\begin{abstract}
We investigate the end-capped oligothiophene derivative $\alpha, \omega$-bis-(dicyanovinylene)-sexithiophene with ethyl side chains (DCV6T) as donor material in heterojunctions with C60. The effect of the substrate temperature on the morphology and related photophysical properties of single DCV6T and mixed DCV6T:C60 layers is investigated. Single layers of DCV6T show crystalline features in $\mathrm{UV}$-visible absorption and $\mathrm{x}$-ray diffraction when grown on a substrate heated to $90{ }^{\circ} \mathrm{C}$. Investigations of DCV6T:C60 mixed layers by atomic force microscopy, UV-visible absorption, and photoluminescence measurements reveal that the elevated substrate temperature induces an increased phase separation between the two materials with larger domain size and higher surface roughness. Based on these observations, we present mixed heterojunction solar cells where the power conversion efficiency $\left(\eta_{\mathrm{PCE}}\right)$ is increased from $1.6 \%$ to $3.8 \%$ by increasing the substrate temperature from 30 to $90{ }^{\circ} \mathrm{C}$, respectively. (C) 2010 American Institute of Physics.
\end{abstract}

[doi:10.1063/1.3271407]

\section{INTRODUCTION}

Currently, organic solar cells are generating increasing interest for future power generation based on their potential low cost, ease of processing, and compatibility to flexible substrates. In 1986, Tang introduced the concept of a donoracceptor (D-A) heterojunction (HJ), which is crucial for an efficient separation of the excitons that are created by photon absorption in an organic layer. ${ }^{1}$ Since then the power conversion efficiencies (PCEs) of organic photovoltaic cells have been steadily increasing and are now reaching above $6 \% .^{2-4}$ There are different concepts of realizing a D-A HJ. It can either be achieved by a planar structure, as it was the case in Tang's solar cell, or it can be made in the form of an interpenetrating network or a so-called bulk or mixed HJ. ${ }^{5-8} \mathrm{Re}-$ cently, also combinations of both concepts, where the mixed layer is sandwiched between planar layers of donor and acceptor were investigated. ${ }^{9,10}$ The major challenge in the optimization of these HJs is to achieve an efficient collection of excitons that are separated at the D-A interface and at the same time provide efficient transport of the created charges. Furthermore, a high absorption is desirable, which means that the layer should be sufficiently thick to absorb all the incoming light. All these efficiencies put together form the external quantum efficiency (EQE) given by

$$
\mathrm{EQE}=\eta_{a} \cdot \eta_{\mathrm{ed}} \cdot \eta_{\mathrm{ct}} \cdot \eta_{\mathrm{cc}}
$$

where $\eta_{a}$ is the efficiency of absorption, $\eta_{\mathrm{ed}}$ is the efficiency of exciton diffusion to an dissociating D-A interface, $\eta_{\mathrm{ct}}$ is the probability that the excitons are dissociated into free

\footnotetext{
${ }^{a)}$ Electronic addresses: david.wynands@iapp.de and wynands@iapp.de. URL: http://www.iapp.de.
}

charge carriers, and $\eta_{\mathrm{cc}}$ is the efficiency of charge transport to the contacts. In planar HJ, only excitons that are created within the distance of the exciton diffusion length $\left(L_{d}\right)$ from the D-A interface can be separated. Since $L_{d}$ is typically as low as $5-30 \mathrm{~nm},{ }^{7,11-15}$ planar HJs are limited by $\eta_{\mathrm{ed}}$, and therefore it is difficult to reach optimized efficiencies. Mixed HJs, on the other hand, are more promising because in a mixed layer of donor and acceptor the distance to a dissociating interface can be only a few nanometers, which ensures that nearly every exciton gets separated into charges within its lifetime. Nevertheless, a perfect homogeneous mixing is not wanted because this impedes the charge transport. To achieve efficient charge transport from the mixed $\mathrm{HJ}$ layer to the contacts, a phase separation between donor and acceptor is needed to form percolation paths. It is mainly this trade-off between large and small phase separation that makes control of the nanoscale morphology of the mixed HJ a crucial prerequisite for the optimization of the solar cell. In polymer solar cells, a large number of studies have addressed the characterization and control of the morphology. Especially, the use of thermal and solvent annealing as well as different composition ratios and solvents turned out to significantly improve the solar cell performance by achieving HJ with higher crystallinity of the donor as well as a better phase separation. ${ }^{16-21}$ In small molecular solar cells, the morphology can also be affected by means of current treatment or enhanced substrate temperature during film deposition. ${ }^{22,23}$ For zinc phthalocyanine:C60 HJ solar cells, performance improvements with efficiencies of up to $2.56 \%$ were reported. ${ }^{24}$ Here, we show that even higher efficiencies can be observed by applying substrate heating to a $\alpha, \omega$-bis(dicyanovinylene)-sexithiophene (DCV6T):C60 HJ solar cell. 


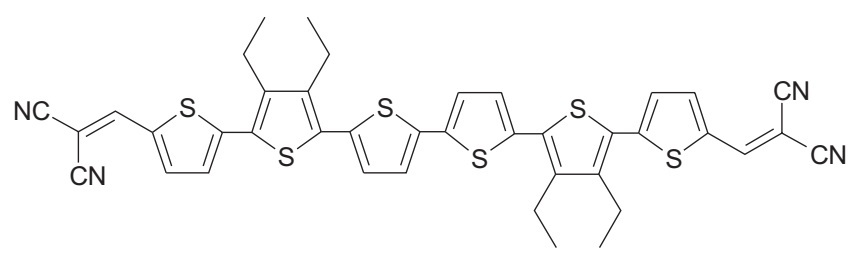

FIG. 1. Chemical structure of the donor absorber material DCV6T-Eth $(2,2,5,5)$.

Oligothiophene derivatives comprising dicyanovinyl end groups are characterized by their low bandgap absorption and high ionization potential (IP). Efficient exciton dissociation in HJs to $\mathrm{C} 60$ was reported by Schueppel et al. ${ }^{25}$ and solar cells based on these materials reach efficiencies of up to $3.4 \%$ with an open circuit voltage of up to $1 \mathrm{~V}^{26}$

The chemical structure of DCV6T that is introduced here is similar to that of the previously discussed DCV6T-Bu(2,2,5,5), ${ }^{10}$ except for the length of the alkyl side chains (Fig. 1). The absorption spectra of DCV6T in solution and in thin film are presented in Fig. 2. The featureless absorption band of the dissolved DCV6T with maximum at $512 \mathrm{~nm}$ indicates rotational freedom of the thiophene rings in the ground state. In contrast, the thin film absorption band is broadened and shifted to lower energies. The modified spectral features of the film are generally explained by planarization of the thiophene rings in the solid state. ${ }^{27}$ The IP of DCV6T determined by ultraviolet photon spectroscopy (UPS) is $5.5 \mathrm{eV}$, thus making it an appropriate match to C60 in D-A HJs for achieving high photovoltages.

In this work, we show how the morphology of single DCV6T and mixed DCV6T:C60 layers can be controlled by the substrate temperature during the layer deposition. Based on these results, solar cells with enhanced efficiencies are presented and the correlations between morphology change and solar cell performance are discussed.

\section{EXPERIMENTAL}

All samples were produced by thermal evaporation in vacuum at a base pressure of $10^{-8}$ mbar. Layer thicknesses

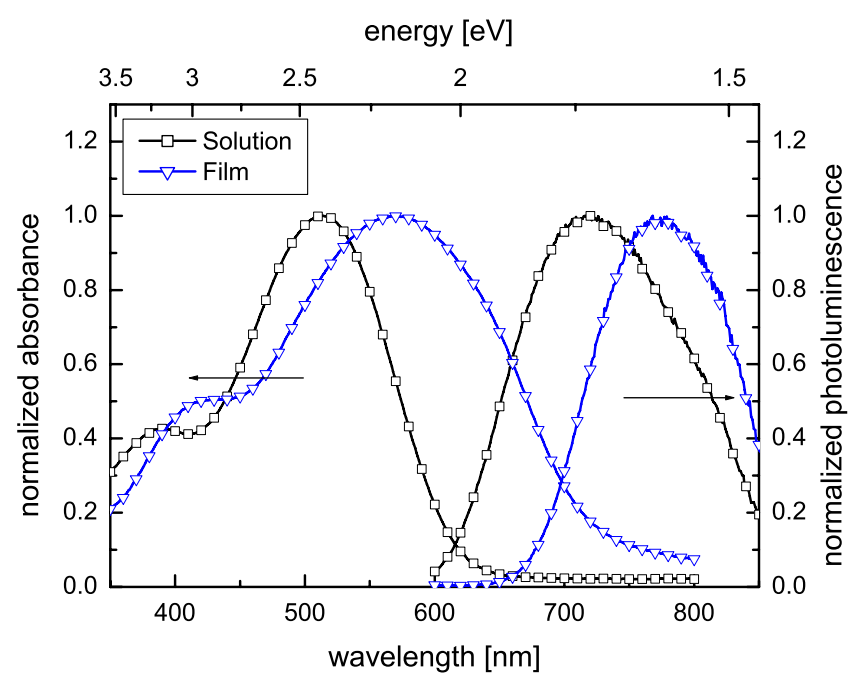

FIG. 2. (Color online) Normalized absorption and photoluminescence spectra of DCV6T dissolved in dichloromethane and of a $30 \mathrm{~nm}$ thin film on quartz substrate. were determined using a quartz crystal monitor that was calibrated before by placing a second crystal at the position of the sample. As substrates quartz glass, indium tin oxide (ITO)-covered glass (Thin Film Devices, Inc., sheet resistance of $30 \Omega / \mathrm{sq}$ ), and Si wafers were used. The substrates were cleaned using aqueous detergent, acetone, ethanol, and isopropanol in ultrasonic bath. For determining the absorption spectra of the single DCV6T thin films grown at different substrate temperatures, quartz substrates were precovered with a $15 \mathrm{~nm}$ thick organic layer of $N, N^{\prime}$-diphenyl- $N, N^{\prime}$-bis ( $4^{\prime}$ - $[N, N$-bis (naphth-1-yl)-amino $]$-biphenyl-4-yl)-benzidine (Di-NPB, Sensient). DCV6T was then deposited at the chosen substrate temperature with a thickness of $20 \mathrm{~nm}$. The absorption of the samples in the UV-visible spectral range was measured in transmission mode using a two-beam spectrometer UV 3100 (Shimadzu Corporation). X-ray diffraction (XRD) analysis was carried out on single DCV6T layers grown on $\mathrm{Si}$ wafers at substrate temperatures of 30 and $90{ }^{\circ} \mathrm{C}$. The nominal thicknesses of the films were 64 and $71 \mathrm{~nm}$, respectively. The measurements were performed with a X'Pert PRO diffractometer (Philips) in Bragg-Brentano $\theta-2 \theta$ geometry using $\mathrm{Cu} K \alpha$ beam with a wavelength of $1.54 \AA$. For the investigation of the morphology of DCV6T:C60 mixed layers, ITO-covered glass substrates were used. First, a $15 \mathrm{~nm}$ thick organic underlayer of C60 was deposited to resemble the solar cell stack. Then, the mixed DCV6T:C60 layers with a thickness of $20 \mathrm{~nm}$ at a ratio of 2:1 (by volume) were deposited at substrate temperatures of 30 and $90{ }^{\circ} \mathrm{C}$. Again, the absorption (optical density) of these samples was measured as described above. Furthermore, steady-state photoluminescence (PL) emission spectra were recorded with a luminescence spectrometer FluoroMax (Spex). The same samples were also used for measuring the surface topology by atomic force microscopy (AFM) using a Digital Instrument Nanoscope IIIa in tapping mode. Finally, solar cells with the following layer structure (thickness is given in nanometers) were produced: ITO/n-C60 (30)/ C60(15)/DCV6T:C60 (20)/BPAPF(5)/p-BPAPF(30)/p$\mathrm{ZnPc}(10) / \mathrm{Au}(50)$. In device $\mathrm{A}$, the substrate was not heated, which corresponds to a substrate temperature of $30{ }^{\circ} \mathrm{C}$. In device $\mathrm{B}$, the substrate was heated to a temperature of $90{ }^{\circ} \mathrm{C}$ during the deposition of the DCV6T:C60 mixed layer. The mixing ratio of the DCV6T:C60 HJ is $2: 1$ by volume. For the hole transport layer (HTL) 9,9-bis[4-( $N, N$-bis-biphenyl-4yl-amino)phenyl]-9H-fluorene (BPAPF, Lumtec) was used because this material provides a high IP of $5.6 \mathrm{eV}$ (determined by UPS) and is therefore well matched to the IP of DCV6T. This is important to avoid transport barriers between the HTL and the donor. ${ }^{10,26,28}$ For doping of C60, the $n$-dopant NDN1 from Novaled AG (Dresden, Germany) was used with a ratio of $3 \mathrm{wt} \%$ (weight percent). BPAPF and zinc phthalocyanine $(\mathrm{ZnPc})$ were doped with the $p$-dopant NDP9 from the same company and ratios of 10 and 3 wt \%, respectively. In all cases the conductivity of the doped layers was above $10^{-6} \mathrm{~S} \mathrm{~cm}^{-1}$ at room temperature, allowing to neglect the voltage drop across these layers. The materials were cleaned at least twice before use by thermal gradient sublimation except for DCV6T (Heliatek GmbH, Dresden, Germany), and the dopants that were used as received. 


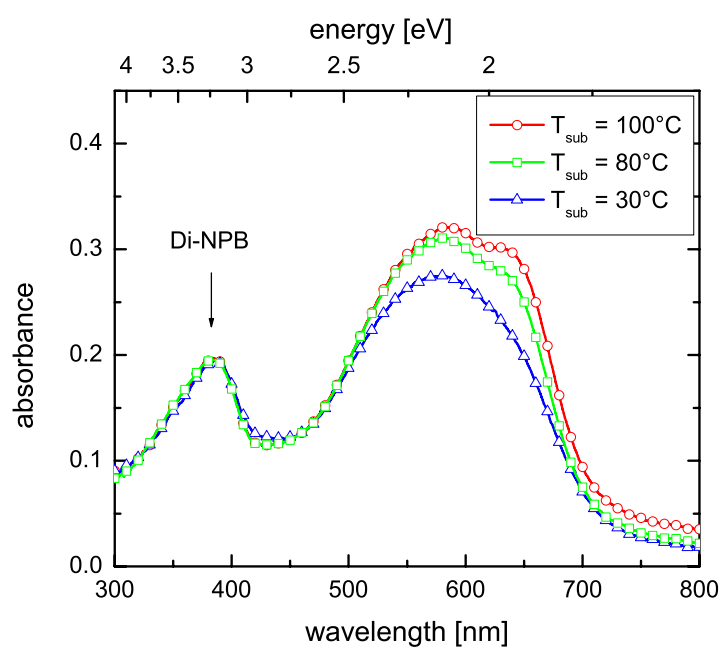

FIG. 3. (Color online) Absorption spectra of DCV6T single layers (20 nm) deposited at various substrate temperatures on top of $15 \mathrm{~nm}$ Di-NPB on quartz substrates.

The current-voltage $(J-V)$ characteristics were recorded with a source measure unit 236 SMU (Keithley) under a sun simulator SC-1200 (Steuernagel) that was tuned to mismatch corrected light intensity, determined by an outdoor reference cell (Fraunhofer Institute for Solar Energy Systems, Freiburg, Germany). The active area of the solar cells is $6.3 \pm 0.2 \mathrm{~mm}^{2}$ and was proven by measuring with an aperture mask. For the EQE measurement, a homemade setup based on a xenon arc lamp, a monochromator (Cornerstone 260), and a lock-in amplifier (Signal Recovery SR 7265) was used. The setup was calibrated with a reference diode (Hamamatsu S1337). Absorption spectra of the solar cells were measured in reflection geometry in a two-beam spectrometer UV 3100 (Shimadzu Corporation) using a pinhole mask with an area of $4.5 \mathrm{~mm}^{2}$.

\section{RESULTS AND DISCUSSION}

\section{A. Morphology of single DCV6T and mixed DCV6T:C60 layers}

Figure 3 illustrates the evolution of the absorption spectra of DCV6T single layers grown on substrates kept at various temperatures on top of Di-NPB. Di-NPB is used as a hole transporting material in organic solar cells and has a characteristic absorption peak at $377 \mathrm{~nm}$. It is known to grow flat amorphous films, thus providing a smooth organic underlayer for the growth of DCV6T. The samples deposited at elevated substrate temperatures show increased absorption at longer wavelengths. The peak position of the absorption band is redshifted, and at higher substrate temperatures, the shoulder at $630 \mathrm{~nm}$ grows to a pronounced peak. The PL emission spectra of the samples on heated substrates (not presented here) show maxima shifted to higher energies compared to the $30{ }^{\circ} \mathrm{C}$ sample. The fine structure in the absorption band of DCV6T grown on heated substrate resembles the solid state absorption features of the regioregular poly(3-alkylthiophene). ${ }^{29}$ For poly(3-hexylthiophene) (P3HT), the lowest energy feature in the absorption spectrum is attributed to interchain aggregation of the polymer and its

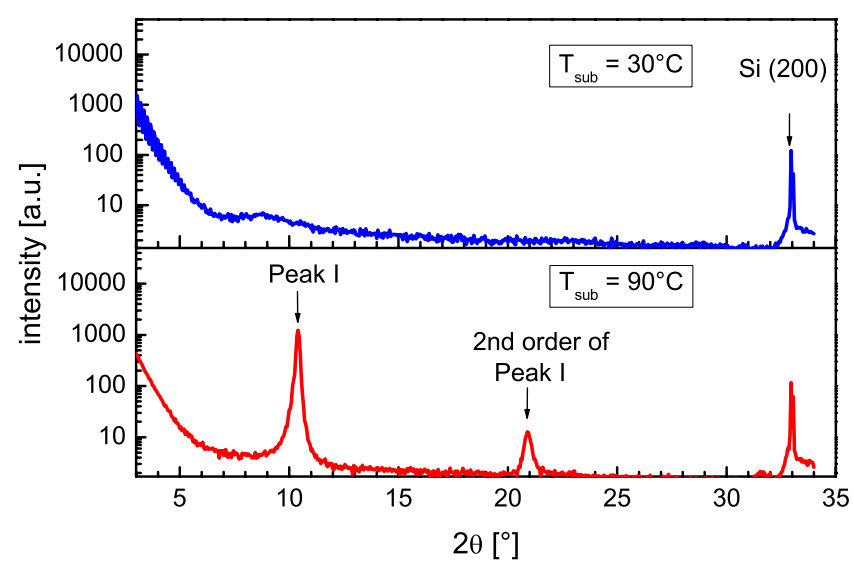

FIG. 4. (Color online) XRD patterns of DCV6T single layers deposited at substrate temperatures of 30 and $90{ }^{\circ} \mathrm{C}$ on $\mathrm{Si}\langle 100\rangle$ wafers.

intensity is thus a characteristic for the degree of order of the polymer film. ${ }^{30}$ Accordingly, we assume that the alterations in the absorption spectra of the DCV6T samples are due to an amorphous to crystalline transformation of the film structure upon condensation on the heated substrate.

XRD patterns of DCV6T films deposited at 30 and $90{ }^{\circ} \mathrm{C}$ on $\mathrm{Si}$ wafers are depicted in Fig. 4 . The $30{ }^{\circ} \mathrm{C}$ sample displays only a weak and broad feature, which implies a rather amorphous structure. In contrast, the XRD pattern of the $90{ }^{\circ} \mathrm{C}$ sample shows two well resolved peaks. The first peak is positioned at $2 \Theta=10.4^{\circ}$ and corresponds to an interplane distance of $8.5 \AA$. The diffraction peak at larger angles is much broader and less intense, its position indicates that it is a second order reflection of the same plane. The diffraction pattern thus confirms the crystalline nature of the DCV6T film grown on the $90{ }^{\circ} \mathrm{C}$ substrate. The exact crystal structure, however, is not yet resolved.

The presented results demonstrate that deposition at elevated substrate temperatures results in improved crystallinity of the single DCV6T layers revealed in more ordered film structure and increased absorption in the red spectral region. Consequently, substrate heating during film growth can be used further to modify the bulk morphology of the DCV6T:C60 mixed layers.

Figure 5 shows the absorption and PL emission spectra of mixed DCV6T:C60 layers grown on substrates at 30 and $90{ }^{\circ} \mathrm{C}$ on top of $\mathrm{C} 60$. The absorption peak at $352 \mathrm{~nm}$ originates from C60, while DCV6T has its main absorption band between 500 and $700 \mathrm{~nm}$. In the $400-500 \mathrm{~nm}$ region both materials contribute to the absorption. In contrast to the absorption of the mixed layer deposited at $30{ }^{\circ} \mathrm{C}$, the absorption of the $90{ }^{\circ} \mathrm{C}$ sample is larger and shifted to longer wavelengths. However, both samples show blueshifted absorption maxima compared to the peak position of the single DCV6T film. Additionally, the heated sample is characterized by a structured band with a shoulder at about $620 \mathrm{~nm}$. The corresponding PL spectra (Fig. 5) also show significant differences. The luminescence of the $30{ }^{\circ} \mathrm{C}$ sample is almost fully quenched, indicating an efficient exciton dissociation. In contrast, the film grown on substrate at elevated temperature shows a luminescence with peak intensity at $752 \mathrm{~nm}$. Compared to a neat DCV6T layer (Fig. 2), the peak position 


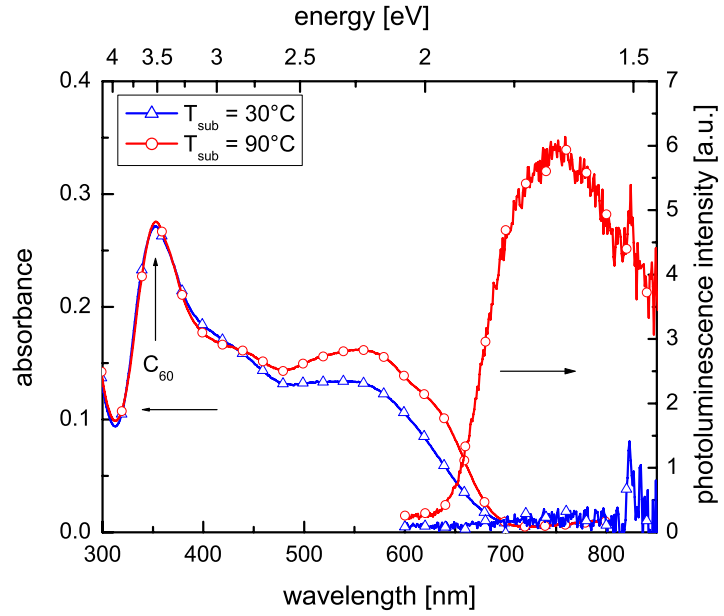

FIG. 5. (Color online) Absorption and PL emission spectra of DCV6T:C60 mixed layers $(2: 1,20 \mathrm{~nm})$ grown at substrate temperatures of 30 and $90{ }^{\circ} \mathrm{C}$ on top of $15 \mathrm{~nm} \mathrm{C60/ITO.}$

is shifted to the blue. The luminescence intensity, however, is much lower. We attribute the more than tenfold gain in the luminescence signal of the $90{ }^{\circ} \mathrm{C}$ sample to an increased degree of phase separation in the mixed layer. A fraction of the excitons generated in the larger DCV6T domains are not able to reach the $\mathrm{C} 60$ interface, thus leading to less efficient quenching of the DCV6T luminescence. In general, the increased radiative recombination of excitons reduces the efficiency of exciton diffusion $\eta_{\mathrm{ed}}$ and thereby the EQE [Eq. (1)].

AFM images of the mixed layer surface are presented in Fig. 6. The micrograph of the $30{ }^{\circ} \mathrm{C}$ sample reveals a smooth surface with uniform features, which suggest an amorphous mixed phase. In contrast, the $90{ }^{\circ} \mathrm{C}$ sample is characterized by structures of increased size comprising grains and larger clusters. The root mean square roughness deduced for the $90{ }^{\circ} \mathrm{C}$ sample is thus correspondingly larger: $2.75 \mathrm{~nm}$ versus $0.54 \mathrm{~nm}$ for the $30{ }^{\circ} \mathrm{C}$ sample. Compared to the $30{ }^{\circ} \mathrm{C}$ sample the vertical scale bar of the heated layer is increased by more than $18 \mathrm{~nm}$.

The depicted similarities between the optical response of the mixed DCV6T:C60 and the single DCV6T films grown on heated substrates (cf. Fig. 3) imply that the DCV6T molecules in the mixed layer have an arrangement closer to that of the molecules in the single layer. The heating of the substrate during deposition leads to higher surface mobility of DCV6T, resulting in improved organization evident by the
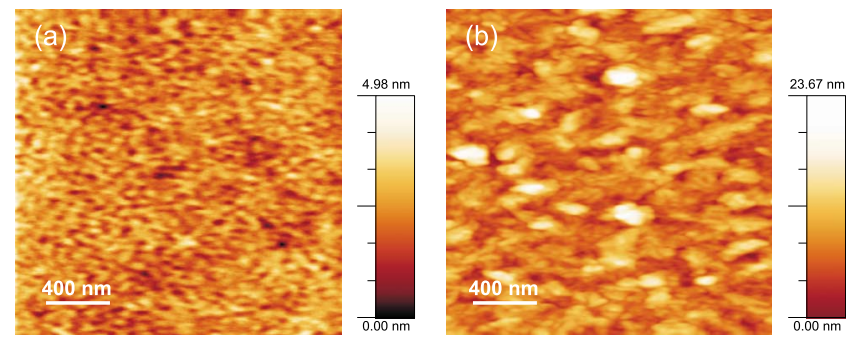

FIG. 6. (Color online) AFM images of DCV6T:C60 mixed layers (2:1, $20 \mathrm{~nm}$ ) deposited at substrate temperatures of (a) $30{ }^{\circ} \mathrm{C}$ and (b) $90{ }^{\circ} \mathrm{C}$ on top of $15 \mathrm{~nm} \mathrm{C60/ITO} \mathrm{(scanned} \mathrm{area} \mathrm{of} 2 \times 2 \mu \mathrm{m}^{2}$ ).

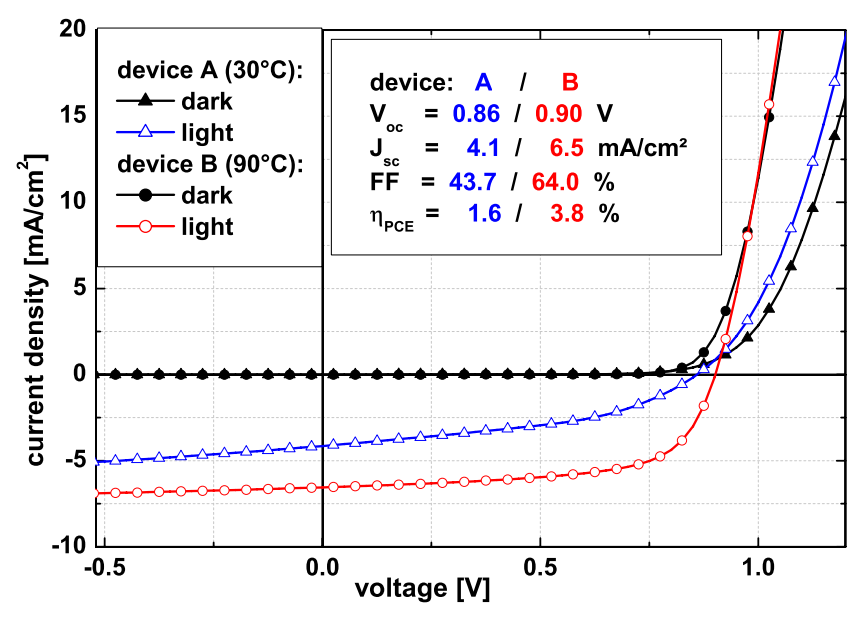

FIG. 7. (Color online) $J-V$ characteristics of DCV6T:C60 mixed HJ solar cells. The substrate temperature during mixed layer growth was $30^{\circ} \mathrm{C}$ for device A, while it was $90{ }^{\circ} \mathrm{C}$ for device B. Measurements were done with intensity corrected for the mismatch. The area of the solar cells is $6.3 \pm 0.2 \mathrm{~mm}^{2}$ determined by measuring with an aperture mask.

structured, redshifted, and increased absorption. The alteration in surface morphology indicates that the degree of intermixing of both components in the blend layer is reduced. The extended phase separation is proven by the enhanced luminescence from the DCV6T domains. The improved structural order and larger domain size should be favorable for the transport of the charge carriers generated. However, some excitons seem to be lost due to recombination in the large DCV6T domains.

\section{B. Bulk heterojunction DCV6T:C60 organic solar cells}

Figure 7 shows the $J-V$ characteristics of devices A and B. The mixed layer in device A was grown at a substrate temperature of $30^{\circ} \mathrm{C}$, whereas in device $\mathrm{B}$, it was grown at a substrate temperature of $90{ }^{\circ} \mathrm{C}$. The $\mathrm{EQE}$ used to correct the $J-V$ measurements for the spectral mismatch are depicted in Fig. 8. The resulting solar cell parameters for device A are $V_{\mathrm{oc}}=0.86 \mathrm{~V}, j_{\mathrm{sc}}=4.2 \mathrm{~mA} \mathrm{~cm}{ }^{-2}, \mathrm{FF}=43.7 \%$, and $\eta_{\mathrm{PCE}}$ $=1.6 \%$. Device B exhibits enhanced performance with $V_{\text {oc }}$ $=0.90 \mathrm{~V}, j_{\mathrm{sc}}=6.5 \mathrm{~mA} \mathrm{~cm}^{-2}, \mathrm{FF}=64.0 \%$, and $\eta_{\mathrm{PCE}}=3.8 \% . J_{\mathrm{sc}}$

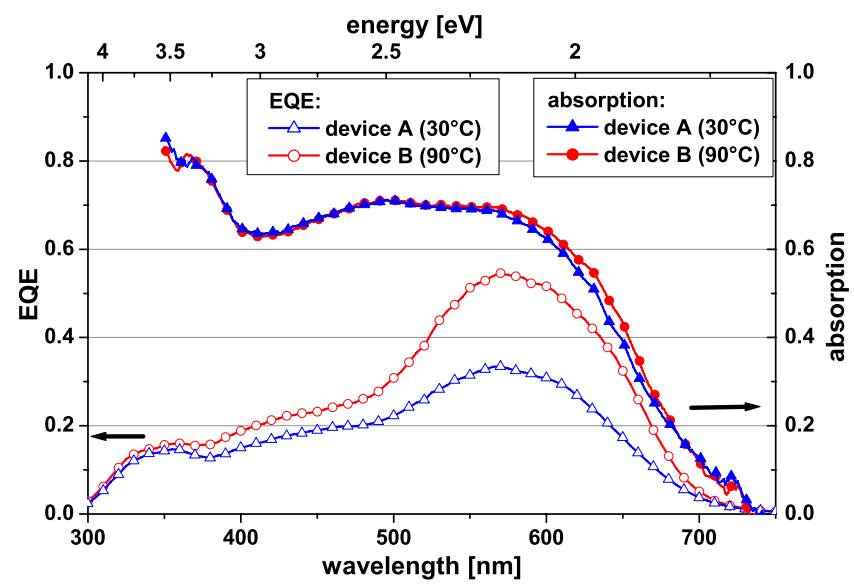

FIG. 8. (Color online) EQE and absorption of DCV6T:C60 mixed HJ solar cells. In device $\mathrm{A}$, the substrate temperature during mixed layer growth was $30{ }^{\circ} \mathrm{C}$, while it was $90{ }^{\circ} \mathrm{C}$ for device $\mathrm{B}$. 
and FF show a strong increase, while $V_{\text {oc }}$ stays nearly constant. Accordingly, $\eta_{\mathrm{PCE}}$ is significantly increased by using the elevated substrate temperature of $90{ }^{\circ} \mathrm{C}$ in device B. In Fig. 8, the total absorption spectra of the devices are shown. Both curves show nearly equal values of about $70 \%$ absorption from 350 to $550 \mathrm{~nm}$. From 550 to $700 \mathrm{~nm}$, device B exhibits an absorption that is only $1 \%-4 \%$ higher than the absorption of device A. This increase in absorption reproduces the observation of increased absorption in single and mixed layers when using substrate heating. Nevertheless, the effect is very small compared to what was measured there. We attribute this to the effects of thin film optics. Although the increased absorption gives rise to an increase in the photocurrent, it only corresponds to a maximum current increase of $0.2 \mathrm{~mA} \mathrm{~cm}^{-2}$. That means that the large increase in current from device $\mathrm{A}$ to $\mathrm{B}$ is not primarily caused by increased absorption, but can only be explained by an increased internal quantum efficiency (IQE). Based on Eq. (1), the IQE can be written as

$$
\mathrm{IQE}=\eta_{\mathrm{ed}} \eta_{\mathrm{ct}} \eta_{\mathrm{cc}}=\frac{\mathrm{EQE}}{\eta_{a}}
$$

Using the measured values for EQE and absorption, we calculate that the maximum IQE of device $\mathrm{A}$ is $50 \%$, while it is $80 \%$ for device B. These values do not take into account the parasitic losses in the nonactive layers that are, however, similar in both devices. The main reason for the increase in the IQE by using the substrate heating is attributed to the change in morphology, providing better phase separation in the mixed HJ. As described above, this increases the domain size of DCV6T and C60 phases and therefore provides more continuous pathways for charge transport. Therefore, the charge collection efficiency is enhanced. This enhancement is also apparent in the development of the slope of the $J-V$ characteristics in the negative bias direction, which is calculated by

$$
s=\frac{J(-1 \mathrm{~V})}{J_{\mathrm{sc}}} .
$$

This parameter measures the electric-field dependency of the photocurrent, indicating the field dependency of the IQE. It is significantly decreased from $s=1.56$ in device A to $s$ $=1.09$ in device $\mathrm{B}$, meaning that in device $\mathrm{A}$ a higher electric field is required to drive the same photocurrent. This explains the gain in $j_{\mathrm{sc}}$ as well as in FF. Another indication for the presence of more continuous pathways for charge transport is the decrease in series resistance from $7.4 \Omega \mathrm{cm}^{2}$ in device A to $4.4 \Omega \mathrm{cm}^{2}$ in device $\mathrm{B}$, which also has a positive effect on the FF. All these parameters show that the electrical performance of the mixed DCV6T:C60 HJ is enhanced when using substrate heating. On the other hand, the above presented PL measurements show that more excitons are lost due to the larger domain size. Nevertheless, the solar cells exhibit a clear increase in $j_{\mathrm{sc}}$, which means that the benefit of increased charge collection efficiency $\left(\eta_{\mathrm{cc}}\right)$ is much larger than the loss in exciton diffusion efficiency $\left(\eta_{\mathrm{ed}}\right)$. Similar observations of performance increase through morphology control are reported for polymer-based P3HT:PCBM mixed HJs so- lar cells upon thermal and solvent annealing. ${ }^{17-21}$ We are dealing here with oligothiophenes and therefore are using a different deposition technique. Nevertheless, we consider our results to be related to the same effects as described in those publications. To study whether the achieved morphology is stable, the solar cells were stored for $360 \mathrm{~h}$ under nitrogen atmosphere and then measured again. No degradation is observed, which shows that there is no further phase separation after the preparation of the solar cells.

\section{CONCLUSIONS}

We have shown that the morphology of the single DCV6T and mixed DCV6T:C60 layers can be influenced by substrate temperature during the deposition. For the studied substrate temperature interval $\left(30-100{ }^{\circ} \mathrm{C}\right)$, the absorption of single DCV6T films becomes structured and is shifted to lower energies with increasing substrate temperature. XRD measurements clearly show a crystalline feature for the single layer grown at heated substrate, which is not present in the sample grown without substrate heating at $30^{\circ} \mathrm{C}$. These results suggest an amorphous to crystalline transition of the film structure upon condensation of the DCV6T molecules on the heated substrates.

In mixed layers of DCV6T:C60, an increased absorption as well as a higher PL signal of DCV6T is observed when a substrate temperature of $90{ }^{\circ} \mathrm{C}$ is used. AFM investigations reveal increased structural size and surface roughness for the heated sample. This indicates an improved demixing between the DCV6T and C60 phases during the mixed layer deposition resulting in favorable phase separation and larger clusters of the respective materials.

The presented solar cells show that the changed morphology achieved by substrate heating improves the solar cell performance. With substrate heating the PCE was raised from $1.6 \%$ to $3.8 \%$. This is mainly a consequence of improved charge collection in the mixed $\mathrm{HJ}$, resulting in improved $j_{\mathrm{sc}}$ as well as FF. In analogy to the experience from polymer solar cells, where control of morphology is one of the key issues of many research efforts, we show that also small molecule solar cells can benefit from morphology control of the mixed HJ layer.

\section{ACKNOWLEDGMENTS}

We thank Selina Olthof for the UPS measurements and the Europäische Fonds für regionale Entwicklung (EFRE) and the Freistaat Sachsen (Project No. 12717/2112) for financial support.

${ }^{1}$ C. W. Tang, Appl. Phys. Lett. 48, 183 (1986).

${ }^{2}$ J. Y. Kim, K. Lee, N. E. Coates, D. Moses, T. Q. Nguyen, M. Dante, and A. J. Heeger, Science 317, 222 (2007).

${ }^{3} 2 \mathrm{~cm}^{2}$ small-molecule organic solar cell, technical report made by heliatek/IAPP, measured by ISE (Freiburg, Germany) in 2009 as having $6.07 \%$ under standard reporting conditions.

${ }^{4} 0.047 \mathrm{~cm}^{2}$ polymer organic cell, technical report made by Solarmer, measured by NREL in 2009 as having $6.77 \%$ under standard reporting conditions.

${ }^{5}$ S. Uchida, J. G. Xue, B. P. Rand, and S. R. Forrest, Appl. Phys. Lett. 84, 4218 (2004).

${ }^{6}$ D. Gebeyehu, B. Männig, J. Drechsel, K. Leo, and M. Pfeiffer, Sol. Energy Mater. Sol. Cells 79, 81 (2003). 
${ }^{7}$ P. Peumans, A. Yakimov, and S. R. Forrest, J. Appl. Phys. 93, 3693 (2003).

${ }^{8}$ H. Hoppe and N. S. Sariciftci, J. Mater. Res. 19, 1924 (2004).

${ }^{9}$ J. G. Xue, B. P. Rand, S. Uchida, and S. R. Forrest, J. Appl. Phys. 98 124903 (2005).

${ }^{10}$ D. Wynands, B. Männig, M. Riede, K. Leo, E. Brier, E. Reinold, and P. Bauerle, J. Appl. Phys. 106, 054509 (2009).

${ }^{11}$ S. Banerjee, A. P. Parhi, S. S. K. Iyer, and S. Kumar, Appl. Phys. Lett. 94 223303 (2009).

${ }^{12}$ Y. Terao, H. Sasabe, and C. Adachi, Appl. Phys. Lett. 90, 103515 (2007)

${ }^{13}$ S. B. Rim, R. F. Fink, J. C. Schoneboom, P. Erk, and P. Peumans, Appl. Phys. Lett. 91, 173504 (2007).

${ }^{14}$ D. E. Markov, C. Tanase, P. W. M. Blom, and J. Wildeman, Phys. Rev. B 72, 045217 (2005).

${ }^{15}$ A. Haugeneder, M. Neges, C. Kallinger, W. Spirkl, U. Lemmer, J. Feldmann, U. Scherf, E. Harth, A. Gugel, and K. Müllen, Phys. Rev. B 59, 15346 (1999)

${ }^{16}$ S. E. Shaheen, C. J. Brabec, N. S. Sariciftci, F. Padinger, T. Fromherz, and J. C. Hummelen, Appl. Phys. Lett. 78, 841 (2001).

${ }^{17}$ F. Padinger, R. S. Rittberger, and N. S. Sariciftci, Adv. Funct. Mater. 13, 85 (2003).

${ }^{18} \mathrm{G}$. Li, V. Shrotriya, Y. Yao, J. S. Huang, and Y. Yang, J. Mater. Chem. 17, 3126 (2007).

${ }^{19} \mathrm{G}$. Li, Y. Yao, H. Yang, V. Shrotriya, G. Yang, and Y. Yang, Adv. Funct. Mater. 17, 1636 (2007).
${ }^{20}$ U. Zhokhavets, T. Erb, H. Hoppe, G. Gobsch, and N. S. Sariciftci, Thin Solid Films 496, 679 (2006).

${ }^{21}$ T. F. Guo, T. C. Wen, G. L. Pakhomov, X. G. Chin, S. H. Liou, P. H. Yeh, and C. H. Yang, Thin Solid Films 516, 3138 (2008).

${ }^{22}$ K. Suemori, T. Miyata, M. Hiramoto, and M. Yokoyama, Jpn. J. Appl. Phys., Part 2 43, L1014 (2004).

${ }^{23}$ M. Vogel, J. Strotmann, B. Johnev, A. C. Lux-Steiner, and K. Fostiropoulos, Thin Solid Films 511, 367 (2006).

${ }^{24}$ S. Pfuetzner, J. Meiss, A. Petrich, M. Riede, and K. Leo, Appl. Phys. Lett. 94, 253303 (2009).

${ }^{25}$ R. Schueppel, K. Schmidt, C. Uhrich, K. Schulze, D. Wynands, J. L. Bredas, E. Brier, E. Reinold, H. B. Bu, P. Bäuerle, B. Männig, M. Pfeiffer, and K. Leo, Phys. Rev. B 77, 085311 (2008).

${ }^{26}$ K. Schulze, C. Uhrich, R. Schüppel, K. Leo, M. Pfeiffer, E. Brier, E. Reinold, and P. Bäuerle, Adv. Mater. (Weinheim, Ger.) 18, 2872 (2006).

${ }^{27}$ M. Turbiez, P. Frere, M. Allain, C. Videlot, J. Ackermann, and J. Roncali, Chem.-Eur. J. 11, 3742 (2005)

${ }^{28}$ C. Uhrich, D. Wynands, S. Olthof, M. K. Riede, S. Sonntag, K. Leo, B. Männig, and M. Pfeiffer, J. Appl. Phys. 104, 043107 (2008).

${ }^{29}$ T. A. Chen, X. M. Wu, and R. D. Rieke, J. Am. Chem. Soc. 117, 233 (1995).

${ }^{30}$ P. J. Brown, D. S. Thomas, A. Kohler, J. S. Wilson, J. S. Kim, C. M. Ramsdale, H. Sirringhaus, and R. H. Friend, Phys. Rev. B 67, 064203 (2003). 